\title{
Business Process Mining ApPlication: A Literature ReVieW
}

\section{Dusanka Dakic, Darko Stefanovic, Ilija Cosic, Teodora Lolic \& Milovan Medojevic}
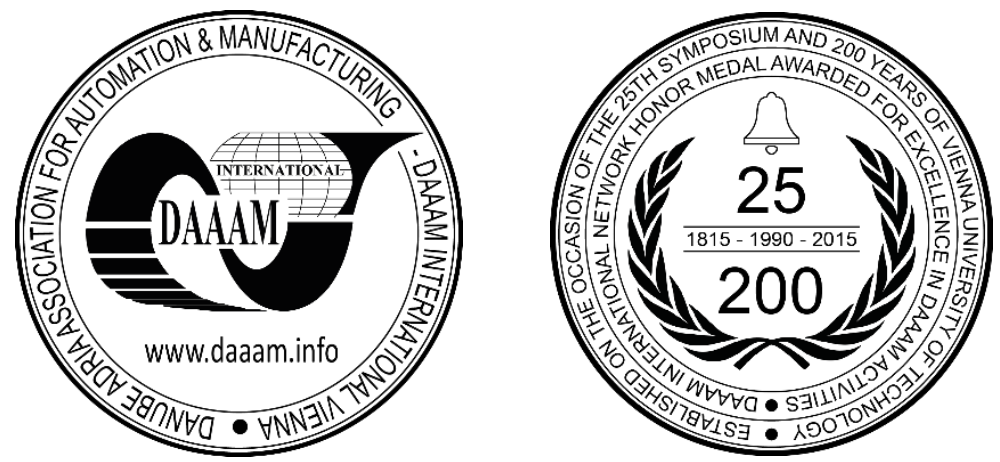

This Publication has to be referred as: Dakic, D[usanka]; Stefanovic, D[arko]; Cosic, I[lija]; Lolic, T[eodora] \& Medojevic, M[ilovan] (2018). Business Process Mining Application: A Literature Review, Proceedings of the 29th DAAAM International Symposium, pp.0866-0875, B. Katalinic (Ed.), Published by DAAAM International, ISBN $978-$ 3-902734-20-4, ISSN 1726-9679, Vienna, Austria DOI: $10.2507 / 29$ th.daaam.proceedings.125

\begin{abstract}
Business process mining is a relatively new and expanding research field, which focuses on analysis of business processes by applying data mining and machine learning techniques on event data. Management, modeling and analysis of business processes are today mainly accomplished through contemporary, process-aware information systems. These enterprise information systems, such as Workflow Management Systems, Enterprise Resource Systems, Customer Relationship Systems, etc. store all process events in some form of event logs. The main idea of business process mining is extraction of event data from event logs in order to automatically construct business process models, compare existing process model with an event log of the same process and extend or improve existing process model. Although business process mining is a topic that received attention in the last decade and has been applied on real-life business processes, not many researches are familiarized with it. To make a contribution to a relevant subject, following research offers an overview of the field and is based on a literature review of relevant papers published on application of business process mining in industry, in the period of ten years. Consequently, meaningful and notable results are discussed, along with guidelines for future research.
\end{abstract}

Keywords: business process mining; data mining; business process management; industrial application; literature review

\section{Introduction}

Business processes present a core of business organizations since the occurrence of process view on the organization. The organization is viewed as a set of business processes, a process system, where processes have interaction and interdependence, with a common goal of creating values. Disciplines such as business process management, modeling and analysis are remaining topics with increasing frequency of appearance, as many vendors are positioning their enterprise information systems as business process management and business process analysis systems $[3,4]$. In today's highly automated business environments, where a modern, complex business process is an "inherently distributed system" [2], organizations are utilizing Process-Aware Information Systems (PAIS). PAIS are supervising conduction of business processes, driven by explicit process models. Examples of these information systems are Enterprise Resource Planning Systems, Supply Chain Management Systems, Customer Relationship Management Systems, Enterprise Asset Management Systems, Hospital Information Systems and many more. 
What these information systems have in common is an explicit process notion and awareness of the processes they support. However, these systems showed strong focus on process automation and little attention to issues like flexibility and diagnosis [1]. Furthermore, even if they offer embedded Business Intelligence (BI) tools, statistical analysis is conducted on manually collected data (e.g. Six sigma measures and reduces the degree of business process variability based on manually collected data) [6]. In this context, the process mining research area has emerged, proposing utilization of data mining techniques to automatically discover process models that are consistent with observed dynamic behavior, compare them to existing process models and to determine the causes of process deviations [1].

As process mining is considered to be one of leading innovations in the field of business process management [7], in 2012. The IEEE has established a Task Force on process mining lead by Wil van der Aalst, from Eindhoven University of Technology, The Netherlands. The task force published a Process Mining Manifesto [5] and introduced process mining as a research field, with description of basic concepts, guiding principles and challenges.

This paper presents overview of process mining as a research field and technique, with focus on basic concepts: events and event logs, types, perspectives, software tools and techniques that can be used while performing process mining. Furthermore, a literature review was conducted, with focus on application of previously mentioned process mining concepts, on industries in which process mining is applied and on motivation for process mining application. The remainder of the paper is organized as follows. Section 2 provides researchers with the insight in process mining field, explaining basic concepts such as event logs, types and perspectives of process mining, contemporary tools and formalisms they include, as well as most current problems in the area. Section 3 describes the research design used in literature review and Section 4 presents literature review results and their brief discussion. Section 5 concludes the paper and suggests future research.

\section{Business process mining: an overview}

Business process mining is a new research field, introduced and defined by previously mentioned IEEE Task Force on process mining. Therefore, the most suitable definition is the one given in the Process Mining Manifesto [5]:

"The idea of process mining is to discover, monitor and improve real processes (i.e., not assumed processes) by extracting knowledge from event logs readily available in today's (information) systems. Process mining includes (automated) process discovery (i.e., extracting process models from an event log), conformance checking (i.e., monitoring deviations by comparing model and log), social network/organizational mining, automated construction of simulation models, model extension, model repair, case prediction, and history-based recommendations."

As shown in Figure 1., process mining prerequisites are: software systems, that support and control real-life business processes and store event data, such as messages, transactions, logs etc., as event logs in some type of a database. Event data is then extracted, filtered and loaded into process mining software, where certain type of process mining can be conducted (discovery, conformance and/or enhancement).

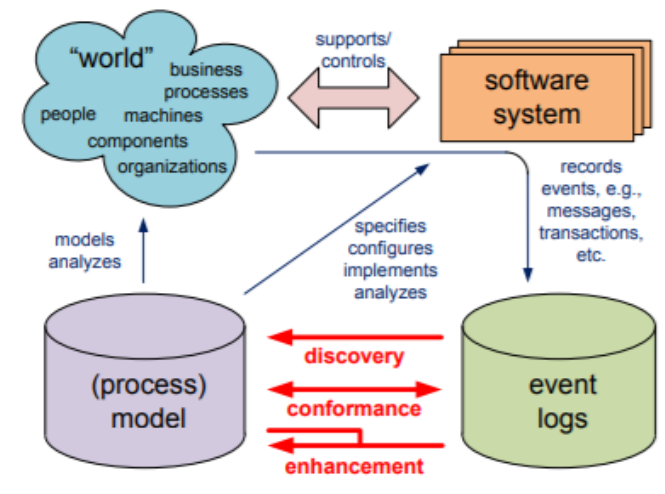

Fig. 1. Process mining context [5]

In the following section, most relevant process mining concepts, as well as software tools and problems are briefly presented.

\subsection{Events and event logs}

It is assumed that an event refers to a process activity or a task, which is a well-defined step in the process and is related to a particular case, i.e. process instance. Another assumption is that these events are ordered [8, 9]. The case or process instance is a specific occurrence or execution of a business process, while activity is an operation, part of a case, that is being executed. An event log stores information about cases and activities, but also information about event performers (person or device executing the activity), event timestamps (moment when the event is triggered) or data elements recorded with the event. 
Process mining activities such as extracting and filtering data from information systems are not trivial, considering that data may be distributed over a variety of sources, event data may be incomplete, an event log may contain outliers, logs may contain events at different level of granularity, etc. Process Mining Manifesto gives following guidelines referring to the event data: events should be trustworthy i.e., it should be safe to assume that the recorded events actually happened and that the event attributes are correct; event logs should be complete i.e., given a particular scope, no events may be missing; any recorded event should have well-defined semantics and the event data should be safe. [5, 9].

\subsection{Process mining types}

Event logs can further be used for conduction of three process mining types: discovery, conformance and enhancement. A process discovery technique produces a process model from an event log, without using any a-priori information about the process and it is the most eminent process mining technique [5].

Conformance compares an existing process model with an event log of the same process and is used to check if reality, as recorded in the log, conforms to the model and vice versa. Conformance checking can be used to: check the quality of documented processes (asses whether they describe reality accurately); to identify deviating cases and understand what they have in common; for auditing purposes; to judge the quality of a discovered process model; to guide evolutionary process discovery algorithms and as a starting point for model enhancement [5]. Conformance checking uses two different types of metrics in order to compare existing process with an event log, which are: fitness, i.e., the extent to which the log traces can be associated with valid execution paths specified by the process model, and appropriateness, i.e., the degree of accuracy in which the process model describes the observed behavior, combined with the degree of clarity in which it is represented [10]. These metrics are referable to two basic conformance checking activities: business alignment, verification that process model and event log are "well-aligned" and auditing, evaluation of the current executions of the process with respect to "boundaries" (given by managers, laws, etc.) [11].

Enhancement extends or improves an existing process model using information about the actual process recorded in event $\log$, with the aim of changing or extending the a-priori model. For instance, by using time stamps in the event log one can extend the model to show bottlenecks, service levels, throughput times and frequencies [5].

\subsection{Process mining perspectives}

Process mining may cover different perspectives. The control-flow or process perspective focuses on the controlflow, i.e., the ordering of activities. The goal of mining this perspective is to find a good characterization of all possible paths, expressed in terms of a Petri net or some other process notation (e.g., EPCs, BPMN, or UML activity diagrams) [5]. Mining the process perspective should answer the question "How" a process is being executed and usually only considers the case and activity attributes of an event $\log$ [5]. The organizational perspective focuses on information about originators in the log, i.e., which actors how are they related. The goal is to either structure the organization by classifying people in terms of roles and organizational units or to show the social network (i.e. relations between individual performers). Mining the organizational perspective should answer the question "Who" is performing the process activities and how are they related, which can be derived from the frequency of passing a case from one performer to another [5]. The case perspective focuses on properties of cases, which are the path in the process, case performers and values of the corresponding data elements. Main goal of this perspective is to observe a case as a whole and to answer the question "What". The time perspective is concerned with the timing and frequency of events and is the least prominent perspective of process mining. When events bear timestamps it is possible to discover bottlenecks, measure service levels, monitor the utilization of resources, and predict the remaining processing time of running cases [5].

\subsection{Process mining software tools and techniques}

Since process mining was first introduced as scientific discipline, with its first software tools, algorithms and techniques, scientific community gave enormous contribution by developing many more. Therefore, many contemporary process mining software tools were developed and are continuously improved, such as: (Celonis Gmbh), Disco (Fluxicon), EDS (StereoLOGIC Ltd), Fujitsu (Fujitsu Ltd) Icaro (Icaro Tech), Icris (Icris), LANA (Lana Labs), Minit (Gradient ECM), myInvenio (Cognitive Technology), ProcessGold (Processgold International B.V.), ProM (Open Source, hosted at TU/e), ProM Lite (Open Source hosted at TU/e), QPR (QPR), RapidProM (Open Source hosted at TU/e), Rialto (Exeura), SNP (SNP Schneider-Neureither \& Partner AG), ARIS PPM ( Software AG). Currently, the most prominent, open-source tool is ProM (Process Mining Framework) ${ }^{1}$, as it offers a variety of plug-ins that enable application of various algorithms and latest developments in process mining research.

If algorithms are classified holistically, there are three main categories of process mining algorithms: Deterministic algorithms, Heuristic algorithms and Genetic algorithms. Deterministic algorithms always generate repeatable models, as all of the data has to be known and process mining output is constant for the given input of variables.

${ }^{1}$ http://www.promtools.org/doku.php 
Example of such algorithm is an $\alpha$-algorithm, one of the simplest and most practical solutions, that generates a Petri Net representation of the process based on casual relations observed in the event log. Heuristic algorithms are commonly used when a predefined algorithmic approach is unable to find an optimal solution and it becomes necessary to implement an approach that looks for a good solution, by trial and error. With genetic algorithms, a solution to a problem is found by starting with an arbitrary starting point, and then searching for a better solution while disregarding inferior solution, where the search is done by combining attributes used for the previous solutions and also introducing random variations. With this approach, the algorithm iteratively improves the population, until a suitable candidate is found ("stop criterion"). This approach is extremely powerful and can extract a huge number of models, although it is rather complex [21].

\subsection{Process mining problems}

Considering that process mining is an emerging discipline, during its application in real-life business processes, several problems and challenges have emerged. The Process Mining Manifesto [5] grouped them into following eleven categories: C1. Finding, merging, and cleaning event data; C2. Dealing with complex event logs with diverse characteristics; C3. Creating representative benchmarks; C4. Dealing with concept drift; C5. Improving the representational bias used for process discovery; C6. balancing between quality criteria; C7. Cross-organizational mining; C8. Providing operational support; C9. Combining process mining with other types of analysis; C10. Improving usability for non experts; C11. Improving understandability for non experts.

Challenges of process mining and their possible solutions have been a topic of interest in the field. Therefore, for further reading, The Process Mining Manifesto [5] offers detailed explanation of every challenge listed above, and [11, $12,13]$ are providing researchers with the state-of-the-art of the most important challenges of process mining and techniques that could solve occurring problems.

\section{Research design and methodology}

Research goal was to gather insightful information about application of process mining in industry, with accent on process mining perspectives, types, branches of industry and business processes that were mined, as well as software tools and techniques used in process mining process. The data source utilized for that purpose is Scopus ${ }^{2}$, the largest abstract and citation database of peer-reviewed literature, which includes scientific journals, books and conference proceedings. Figure 2. shows the literature review process and the number of papers identified at each stage.

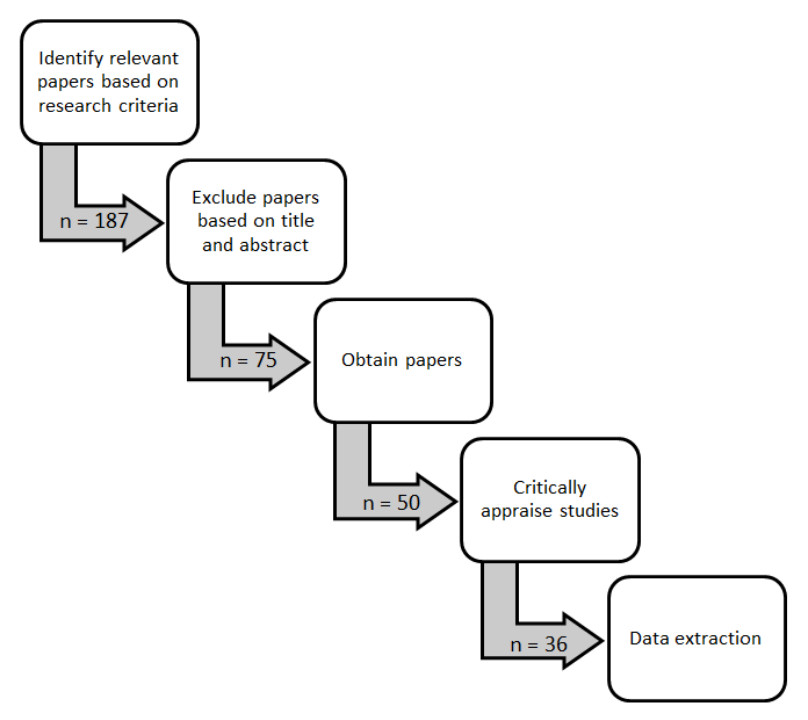

Fig. 2. Literature review process

Identification of relevant papers based on research criteria resulted in 187 eligible papers. Research criteria is built upon following search terms: process mining AND (application OR industry OR case study) AND (business process OR information systems OR business process management), that could occur in title, abstract or keywords. Furthermore, papers were limited to articles and conference papers, published between years 2009 and 2018 and written in English. The citation rate for papers published between 2009 and 2013 was set to 10, in order to exclude irrelevant studies. Relevant papers were imported into Mendeley, where title and abstract review was conducted, resulting in exclusion of 112 papers.

${ }^{2}$ https://www.scopus.com/ 
At this stage, papers where mainly excluded because they focused only on topic of data mining, not process mining, did not present practical applications of process mining techniques in industry or only tackled the topic of process mining problems and solutions. In the next stage of review, due to limited access to databases, a number of papers that met the criteria were omitted from the final selection, which resulted in 50 obtained papers suitable for the next stage critical appraisal of studies. After reading 50 papers, 36 papers where accepted as relevant, credible, insightful and rigor enough to be included in data extraction. Data extraction was focused on information about process mining perspectives, process mining types, analysed industries, business processes and their types, as well as utilized process mining software tools and algorithmsltechniques. After importing extracted data in Microsoft Excel, further analysis was conducted, focusing on frequency of appearance of the concepts, as well as detection of significant relationships between them.

\section{Research results and discussion}

This chapter presents frequency of appearance of perspectives and types of the process mining, industries in which they were applied and on which processes, as well as the tools and algorithms utilized. Subsequently, results are summarized and the most notable observations are discussed.

\subsection{Process mining perspectives}

Table 1. presents distribution of papers based on process mining perspective used and ranking of those perspectives based on their occurrence. Many papers have applied more than one perspective, although there was no significant pattern by which they combined perspectives.

\begin{tabular}{cccc}
\hline Perspective & Papers & Percent \\
\hline \multirow{2}{*}{ Control-flow } & {$[14,15,16,17,18,20,21,22,23,24,25,26,27,28,29,30,31,32,33,34,35,36,37,38,39$,} & $94 \%$ \\
& $40,41,42,43,44,46,47,48,49]$ & $63 \%$ \\
\hline Case/Time & {$[14,15,20,21,24,25,27,28,29,30,31,32,33,34,35,36,37,38,40,43,44,47,49]$} & $22 \%$ \\
\hline Organizational & {$[16,19,25,27,29,34,35,45]$} & \\
\hline
\end{tabular}

Table 1. Distribution of applied process mining perspectives

The control-flow perspective is applied in nearly every study, which is not unexpected, as it is a base for further process analysis. The case and time perspectives appeared to be used together in majority of the papers, so they are presented as one perspective that is applied in $63 \%$ percent of the papers, mostly for: analysis of throughput times [14, $15,27,28,29,30,33,34,36,49]$, discovering patterns and case frequencies [20, 24, 25, 21, 27, 28, 30, 31, 32, 35, 36, $37,43,44,47,49]$, determining bottlenecks and infrequent behavior [21, 28, 29, 32, 34, 36, 37, 43, 49], attribute and resource analysis $[25,36,38,40,44,47,49]$, discovering feedback loops [14, 20, 21] and time trend and waiting times analysis $[14,21,24,25,30,33,35,43,44]$.

Organizational perspective was used only in $22 \%$ of the papers, although it was as useful as other perspectives. In [16], the researches used process mining techniques to discover the structure of main control room crew in a nuclear plant, based on their communication contents being uttered in the course of coping with the training scenario. Furthermore, in [19] researchers discovered role interaction models in Emergency Room (ER), through the use of reallife clinical data and process mining techniques, providing relevant insights about how healthcare professionals collaborate and uncovering opportunities for process improvement. In [25] focus was on analyzing behavioral learner data through the application of process mining techniques specifically targeting a complex problem solving process, with findings showing that certain behavioral patterns can indeed be associated with better/worse outcomes in terms of reaching a satisfactory model quality. In [27, 34] role analysis was performed, in order to check on the efficiency of the segregation of duty. In [29], researchers generated team flow process model, where a flow represents the sequence of teams that worked on the same document. In [35] organizational mining was used to determine if there is ping-pong behavior occurring during handover of work between teams. In [45], organizational mining was used for mapping of interactions occurring in the process and defining areas with the highest numbers of interactions.

\subsection{Process mining types}

Table 2. presents distribution of process mining types in reviewed papers, sorted based on frequency of application.

\begin{tabular}{ccr}
\hline Type & Papers & Percent \\
\hline Discovery & {$[14-49]$} & $100 \%$ \\
\hline Enhancement & {$[14,15,19,20,21,24,25,28,29,30,32,33,34,35,36,37,38,40,43,44,43,44,47,49]$} & $60 \%$ \\
\hline Conformance & {$[14,17,20,21,23,24,27,28,29,31,38,40,44,46,48]$} & $42 \%$ \\
\hline
\end{tabular}

Table 2. Distribution of applied process mining types 
It is important to emphasize that by enhancement every improvement of the process was taken into account, as not many researchers used enhancement techniques to generate improved or extended model of the process, but merely suggested improvements and problem solutions. Improvements they suggested are corresponding to problems found with time/case process mining perspective, which are listed in 4.1. Important observation is that every application of time/case perspective on discovered processes resulted with positive outcome, e.g., found a problem and offered a suggestion for improvement. Therefore, every enhancement paper listed in Table 2. is interpreted in 4.1. as paper that applied caseltime perspective, except [19], where application of organizational perspective enabled improvements.

Conformance checking, as the least applied process mining type, was applied in $42 \%$ percent of the papers, implying that researchers commonly rely on all three process mining types. Motivation for application of conformance checking, as stated in papers, were comparison of discovered model to existing, reference model, checking if reality conforms to the model and vice versa in order to detect deviations and make suggestions for improvements of adherence process model. Generated and existing reference process models (in some cases reference process model was developed by researchers by interviewing managers and relevant company staff) had to be quantified for direct comparison, therefore researchers used fitness and appropriateness metrics, mostly in ProM software tools (in 96\% of the papers, only in [40] researchers chose Disco).

\subsection{Industries and processes}

Table 3. presents twelve identified industries in which process mining was applied and their participation in the total number of papers reviewed.

\begin{tabular}{ccc}
\hline Industry & Papers & Percent \\
\hline Healthcare & {$[15,18,19,24,30,32,39,40,45,47]$} & $28 \%$ \\
\hline IT & {$[17,22,23,26,46]$} & $14 \%$ \\
\hline Finance & {$[27,29,36,42]$} & $11 \%$ \\
\hline Manufacturing & {$[14,20,35]$} & $8 \%$ \\
\hline Education & {$[38,44,25]$} & $8 \%$ \\
\hline Government & {$[28,34,41]$} & $8 \%$ \\
\hline Energy (Oil, gas and nuclear industry) & {$[16,21,28]$} & $8 \%$ \\
\hline Agriculture & {$[28,49]$} & $6 \%$ \\
\hline Logistics & {$[33]$} & $3 \%$ \\
\hline Telecommunication & {$[43]$} & $3 \%$ \\
\hline News media & {$[48]$} & $3 \%$ \\
\hline Tourism & {$[37]$} & $3 \%$ \\
\hline
\end{tabular}

Table 3. Process mining industries

The healthcare industry uses process mining abundantly, being applied in $28 \%$ of the papers. Considering process mining types, the measure in which discovery and enhancement were applied, corresponds to the average for all papers, presented in 4.2. However, conformance checking was performed in $20 \%$ of the papers, against $42 \%$ of papers from all industries. For performance of process mining, researchers used ProM in 22\%, Disco in 66\% and both in $11 \%$ of the papers, differing from average values for all papers, presented in 4.4. Processes that were the topic of process mining in healthcare are: Patient pathway (occurring in $70 \%$ of the papers), with $[15,19,30,32]$ focusing on patient pathway in emergency department and [39, 45, 47] focusing on patient pathway in general, outpatient process [24], usage of medical mobile application [18], generating personalized healthcare process [40].

IT industry is detected in $14 \%$ of the papers. Analysis of papers with focus on process mining types, perspectives and software tools have shown some interesting results. In particular, conformance checking was performed in $60 \%$ of the papers, but more suprisingly, enchancement suggestions were not achieved in any paper, as case, time and organizational perspectives were not applied. Furthermore, for process discovery and mining of control-flow perspective, only ProM software tool was used. Process mining is used in IT industry for: software process assesment $[17,23]$, discovery of business process emedded in a legacy system [22], detection of abnormal user activity in social network websites [26], discovery of incidents and requests handling process in IT service management [46].

Finance industry is identified in $11 \%$ of the papers, with intensified use of organizational perspective $(50 \%$, compared to average of $22 \%$ for all papers), case/time perspective (75\%, compared to average of $63 \%$ for all papers) and consequently, enhancement, appearing in $75 \%$ of the papers in finance industry. Process mining is used in finance for: detecting internal transcation fraud mitigation in a procurement process [27], analysis of DMS in a financial services organization [29], analysis of loan and overdraft approval processs in a bank [36] and analysis of insurance claims settlement process.

Education, Government, Energy (Oil, gas and nuclear industry), Agriculture, Logistics, Telecommunication, News media and Tourism are industries that appeared in less than $10 \%$ percent of the papers, and do not differ from other papers in terms of process mining types, perspectives and utilizied software tools. 


\subsection{Software tools and algorithms}

After reviewing papers and extracting data concerning software tools, algorithms and techniques used for process mining, most important data is presented in following tables. Tools that are utilized in every paper are ProM and Disco, with ProM being a dominant tool, used in $75 \%$ and Disco used in $44 \%$ of the papers. In several papers, both ProM and Disco were used, therefore table 4. presents distribution of used tools relative to papers. ProM was previously mentioned as the currently most prominent process mining software tools, offering an open source platform with numerous, available plug-ins, enabling a wide scope of analysis. On the other hand, Disco is simple, fast and the most efficient log management and filtering framework, with intuitive GUI and visual representation.

\begin{tabular}{ccr}
\hline Tool & Papers & Percent \\
\hline ProM $^{3}$ & {$[14,17,21,22,23,26,27,28,29,30,33,34,38,41,42,44,45,46]$} & $50 \%$ \\
\hline Disco & {$[15,18,19,36,39,40,47]$} & $18 \%$ \\
\hline ProM and Disco & {$[20,25,31,32,35,37,43,48]$} & $22 \%$ \\
\hline
\end{tabular}

Table 4. Distribution of used process mining software tools

In order to analyse why certain tools and algorithms were used, papers were reviewed more closely. Table 5. presents which algorithms were used for control-flow mining and process discovery, and in which tool. It can be concluded that the Fuzzy miner is the most used algorithm, used almost equally in ProM (45\%) and Disco (55\%). However, Heuristic Miner, Genetic algorithm and $\alpha$-algorithm were used only in ProM.

\begin{tabular}{ccc}
\hline Algorithm/technique & Papers & Percent \\
\hline \multirow{2}{*}{ Fuzzy miner } & {$[17,24,27,28,30,32,34,35,38,42]$ ProM } & $66 \%$ \\
\cline { 2 - 3 } & {$[15,18,19,25,36,37,39,40,43,47,48,49]$ Disco } & \\
\hline Heuristic miner & {$[14,20,21,23,24,28,29,30,31,32,33,35,37,38,41,43,44]$ ProM } & $49 \%$ \\
\hline Genetic miner & {$[22,26,32,46]$ ProM } & $11 \%$ \\
\hline$\alpha$-algorithm & {$[26,32,33]$ ProM } & $8 \%$ \\
\hline
\end{tabular}

Table 5. Process mining algorithms

Furthermore, when case, time or organization perspective were mined, researchers used additional techniques (usually ProM plug-ins), such as Dotted Chart, Performance Sequence Analysis, LTL checker, Coloured Petri Net, Organization miner, Social Network Miner and Handover Of Work algorithm. When performing more in-depth analysis using Disco, researchers used fuzzy mining algorithm and variant analysis. Though not as rich in techniques as ProM, Disco was proved to be user friendly, very fast on big event logs while discovering high-level knowledge, capable of handling complex processes, especially helpful for the pre-processing and exportation of data and generating an intuitive process map which can be zoomed in and zoomed out to provide more details or more generic process according to the need of the user. Furthermore, with its implementation of fuzzy mining algorithm, Disco was able to mine the case/time perspective, although for more detail and insightful mining, researchers leaned toward ProM, considering its numerous plug-ins.

\subsection{Results discussion}

Analysis of process mining perspectives showed that control-flow perspective is used most abundantly, following with case and time and organizational perspectives. Case and time perspectives are the most rewarding and valuable perspectives and clearly show the importance and usefulness of process mining, as every application of case and time perspective resulted with positive outcome e.g., detected problems and implied suggestions for improvements, leading to the fact that case and time perspectives and enhancement are directly correlated. Considering process mining types, when performing conformance checking, researchers used ProM in even $96 \%$ of the papers, implying that for this particular activity, ProM offers more suitable techniques than Disco. Furthermore, several important observations have been made considering industries. Similairly to application of Data Mining in healthcare industry [50], which holds great potential to enable health systems to systematically use data and analytics to identify inefficiencies and best practices, process mining apperas to be equally beneficial and applied. Healthcare industry differed from average values for all industries, with small percent of researchers focusing on conformance checking and with extensive use of Disco, instead of ProM, for control-flow discovery. IT industry, however, showed above the average use of conformance checking, utilized only ProM for all performed activities, and has not used case or time perspective in any paper, resulting with no enhancement and suggestions for improvement. As software tools are considered, ProM appeared to be the most dominant tool, although it is important to accentuate that when control-flow discovery was considered, Disco was utilized equally as ProM, because of its convenience and practicality.

${ }^{3}$ In 3 papers, other tools were used in combination with ProM [26, 27, 46] 


\section{Conclusion}

In the study presented, overview of process mining research area was given, as well as a literature review based on 36 process mining application papers. Contribution of this literature review is a list of relevant, credible, insightful and rigor papers describing application process mining in industry, with comprehensive overview of process mining concepts (types, perspectives, industries and processes, software tools and techniques), including list of papers in which the concepts were used and the motivation for their utilization. Furthermore, after data analysis, several meaningful observations have been made. The most notable conclusion is that with utilization of case and time perspectives, process mining, without exception, enables detection of problems and suggestions for improvement, and is extremely fruitful discipline, applicable in different industries and on diverse process types.

Future work could focus on a broader scope of papers, including more index databases and taking into consideration papers that focused on solving process mining problems and applied newly developed methodologies. Moreover, literature review could include analysis of pre-processing and filtering activities as well, as these activities appeared to be complex and problematic.

\section{References}

[1] Van der Aalst, W. M., La Rosa, M., \& Santoro, F. M. (2016). Business process management, Business \& Information Systems Engineering, Vol. 58, No. 1, 2016, pp. 1-6, ISSN: 1867-0202, DOI https://doi.org/10.1007/s12599-015-0409-x

[2] Smirnov, S., Reijers, H. A., Weske, M., \& Nugteren, T. (2012). Business process model abstraction: a definition, catalog, and survey, Distributed and Parallel Databases, Vol. 30, No. 1, 2012, pp. 63-99, ISSN: 1573-7578, DOI https://doi.org/10.1007/s10619-011-7088-5

[3] Suman, S. \& Pogarcic, I. (2016). Development of ERP and Other Large Business Systems in the Context of New Trends and Technologies, Proceedings of the 27th DAAAM International Symposium, pp.0319-0327, B. Katalinic (Ed.), Published by DAAAM International, ISBN 978-3-902734-08-2, ISSN: 1726-9679, Vienna, Austria, DOI: 10.2507/27th.daaam.proceedings.047

[4] Van der Aalst, W. M. \& Weijters, A. J. M. M. (2004). process mining: a research agenda, Computers in Industry, Vol. 53, No. 3, 2004, pp. 231-244, ISSN: 0166-3615, DOI: https://doi.org/10.1016/j.compind.2003.10.001

[5] Van der Aalst, W. M. et al. (2012). process mining Manifesto, In: BPM 2011 Business Process Management Workshops, Lecture Notes in Business Information Processing, Vol 99., Daniel F., Barkaoui K., Dustdar S. (eds), pp. 169-194, Springer, ISBN: 978-3-642-28107-5, Berlin, Heidelberg

[6] Breyfogle III, F. W. (2003). Implementing six sigma: smarter solutions using statistical methods, John Wiley \& Sons, ISBN: 978-0471265726, Hoboken, New Jersey

[7] Van der Aalst, W. M. (2013). Business process management: a comprehensive survey, ISRN Software Engineering, Hindawi Publishing Corporation, Vol. 2013, Article ID: 507984, 37 pages, DOI: http://dx.doi.org/10.1155/2013/507984

[8] Van der Aalst, W. M., van Dongen, B. F., Herbst, J., Maruster, L., Schimm, G., \& Weijters, A. J.M.M. (2003). Workflow mining: A survey of issues and approaches, Data \& knowledge engineering, Vol. 47, No. 2, 2003 , pp. 237-267, ISSN: 0169-023X, DOI: https://doi.org/10.1016/S0169-023X(03)00066-1.

[9] Van Der Aalst, W.M. (2012). process mining: Overview and opportunities. ACM Transactions on Management Information Systems (TMIS), Vol. 3, No. 2, 2012, pp. 7:1--7:17, ISSN: 2158-656X, DOI: $10.1145 / 2229156.2229157$

[10] Rozinat, A. \& Van Der Aalst, W.M. (2008). Conformance checking of processes based on monitoring real behavior. Information Systems, Vol. 33, No. 1, 2008, pp. 64-95, ISSN: 0306-4379, DOI: 10.1016/j.is.2007.07.001

[11] Burattin, A. (2013). Applicability of process mining Techniques in Business Environments, Ph.D. Dissertation,

[12] Department of Applied Mathematics and Computer Science, Technical University of Denmark, Kongens Lyngby, Denmark

[13] Tiwari, A., Turner, C. J. \& Majeed, B. (2008). A review of business process mining: state-of-the-art and future trends. Business Process Management Journal, Vol. 14, No. 1, 2008., pp. 5-22., ISSN: 1463-7154, DOI: https://doi.org/10.1108/14637150810849373

[14] R'bigui, H. \& Cho, C. (2017). The state-of-the-art of business process mining challenges. International Journal of Business Process Integration and Management, Vol. 8, No. 4, 2017., pp. 285-303, ISSN: 1741-8763, DOI: https://doi.org/10.1504/IJBPIM.2017.088819

[15] Rozinat, A., de Jong, I. S. M., Günther, C. W., \& Van Der Aalst, W. M. P. (2009). Process mining applied to the test process of wafer scanners in ASML, IEEE Transactions on Systems, Man and Cybernetics Part C: Applications and Reviews, Vol. 39, No. 4, 2009., pp. 474-479., ISSN: 1558-2442, DOI: http://doi.org/10.1109/TSMCC.2009.2014169

[16] Perimal-Lewis, L., Teubner, D., Hakendorf, P., \& Horwood, C. (2016). Application of process mining to assess the data quality of routinely collected time-based performance data sourced from electronic health records by validating process conformance, Health Informatics Journal, Vol. 22, No. 4, 2016., pp. 1017-1029., DOI: http://doi.org/10.1177/1460458215604348 
[17] Park, J., Jung, J.-Y., \& Jung, W. (2016). The use of a process mining technique to characterize the work process of main control room crews: A feasibility study, Reliability Engineering and System Safety, 2016., Vol. 154, pp. 3141, ISSN: 0951-8320, DOI: http://doi.org/10.1016/j.ress.2016.05.004

[18] Kurniati, A. P., \& Atastina, I. (2015). Implementing process mining to improve COBIT 5 assessment program or managing operations (Case study: A university blog), Journal of Theoretical and Applied Information Technology, Vol. 72, No. 2, pp. 191-198

[19] Huang, C., Cai, H., Li, Y., Du, J., Bu, F., \& Jiang, L. (2017). A process mining Based Service Composition Approach for Mobile Information Systems, Mobile Information Systems, 2017., Vol. 2017, Article ID 3254908, 13 pages, DOI: http://doi.org/10.1155/2017/3254908

[20] Alvarez, C., Rojas, E., Arias, M., Munoz-Gama, J., Sepúlveda, M., Herskovic, V., \& Capurro, D. (2018). Discovering role interaction models in the Emergency Room using process mining, Journal of Biomedical Informatics, Vol. 78, 2018., pp. 60-77., ISSN: 1532-0464, DOI: http://doi.org/10.1016/j.jbi.2017.12.015

[21] Mahendrawathi, E. R., Arsad, N., Astuti, H. M., Kusumawardani, R. P., \& Utami, R. A. (2018). Analysis of production planning in a global manufacturing company with process mining, Journal of Enterprise Information Management, Vol. 31, No. 2, 2018., pp. 317-337., DOI: http://doi.org/10.1108/JEIM-01-2017-0003

[22] Greyling, B. T., \& Jooste, W. (2017). The application of business process mining to improving a physical asset management process: A case study, South African Journal of Industrial Engineering, Vol. 28, No. 2, pp. 120-132., DOI: http://doi.org/10.7166/28-2-1691

[23] Pérez-Castillo, R., Weber, B., De Guzmán, I. G.-R., \& Piattini, M. (2011). process mining through dynamic analysis for modernising legacy systems, IET Software, Vol. 5, No. 3, pp. 304-319., DOI: http://doi.org/10.1049/iet-sen.2010.0103

[24] Samalikova, J., Kusters, R. J., Trienekens, J. J. M., \& Weijters, A. J. M. M. (2014). process mining support for Capability Maturity Model Integration-based software process assessment, in principle and in practice. Journal of Software: Evolution and Process, Vol. 26, No. 7, pp. 714-728., DOI: http://doi.org/10.1002/smr.1645

[25] Cho M., Song M., Yoo S. (2014) A Systematic Methodology for Outpatient Process Analysis Based on Process Mining. In: Ouyang C., Jung JY. (eds) Asia Pacific Business Process Management. AP-BPM 2014. Lecture Notes in Business Information Processing, vol 181. Springer, Cham, DOI: https://doi.org/10.1007/978-3-319-08222-6_3

[26] Sedrakyan, G., De Weerdt, J., \& Snoeck, M. (2016). Process-mining enabled feedback: "tell me what i did wrong" vs. "tell me how to do it right." Computers in Human Behavior, Vol. 57, 2016., pp. 352-376., ISSN: 0747-5632, DOI: http://doi.org/10.1016/j.chb.2015.12.040

[27] Sahlabadi, M., Muniyandi, R. C., \& Shukur, Z. (2014). Detecting abnormal behavior in social network websites by using a process mining technique. Journal of Computer Science, 2014., Vol. 10, No. 3, pp. 393-402., ISSN: 15493636, DOI: http://doi.org/10.3844/jcssp.2014.393.402

[28] Jans, M., Van Der Werf, J. M., Lybaert, N., \& Vanhoof, K. (2011). A business process mining application for internal transaction fraud mitigation. Expert Systems with Applications, Vol. 38, No. 10, 2011., pp. 1335113359., ISSN: 0957-4174, DOI: http://doi.org/10.1016/j.eswa.2011.04.159

[29] Măruşter, L., \& Van Beest, N. R. T. P. (2009). Redesigning business processes: A methodology based on simulation and process mining techniques. Knowledge and Information Systems, Vol. 21, No. 3, 2009., pp. 267297. ISSN: 0219-3116, DOI: http://doi.org/10.1007/s10115-009-0224-0

[30] De Weerdt, J., Schupp, A., Vanderloock, A., \& Baesens, B. (2013). Process mining for the multi-faceted analysis of business processes - A case study in a financial services organization. Computers in Industry, Vol. 64, No. 1, 2013., pp. 57-67., ISSN: 0166-3615, DOI: http://doi.org/10.1016/j.compind.2012.09.010

[31] Partington, A., Wynn, M., Suriadi, S., Ouyang, C., \& Karnon, J. (2015). Process mining for clinical processes: A comparative analysis of four australian hospitals. ACM Transactions on Management Information Systems, Vol. 5, No. 4, 2015., pp. 15-18, ISSN: 2158-656X, DOI: http://doi.org/10.1145/2629446

[32] Kim, E., Kim, S., Song, M., Kim, S., Yoo, D., Hwang, H., \& Yoo, S. (2013). Discovery of outpatient care process of a tertiary university hospital using process mining. Healthcare Informatics Research, Vol. 19, No. 1, 2013., pp. 42-49. ISSN: 2093-3681, DOI: http://doi.org/10.4258/hir.2013.19.1.42

[33] Rojas, E., Sepúlveda, M., Munoz-Gama, J., Capurro, D., Traver, V., \& Fernandez-Llatas, C. (2017). Questiondriven methodology for analyzing emergency room processes using process mining. Applied Sciences (Switzerland), Vol. 7, No. 3., 2017., ISSN: 2076-3417, DOI: http://doi.org/10.3390/APP7030302

[34] Liv, I. \& Lepik, O., Business Process Mining in Warehouses: a Case Study, Proceedings of the 11th International Baltic Conference, Baltic DB\&IS 2014, Haav, H. M., Kalja, A., \& Robal, T.(eds.), pp. 387-394, Published by TUT Press, Tallinn

[35] Bozkaya, M., Gabriels, J., \& Van Der Werf, J. M. (2009). Process diagnostics: A method based on process mining. In Proceedings - International Conference on Information, Process, and Knowledge Management, eKNOW 2009, pp. 22-27, IEEE, DOI: http://doi.org/10.1109/eKNOW.2009.29

[36] Hevia, J., \& Saint-Pierre, C. (2013). Business processing intelligence challenge (BPIC): Case study: Analizing volvo information with process mining. In CEUR Workshop Proceedings, Vol. 1052. , ISBN: 978-1-4244-3362-9, IEEE, DOI: https://doi.org/10.1109/eKNOW.2009.29 
[37] autista A.D., Wangikar L., Akbar S.M.K. (2013) Process Mining-Driven Optimization of a Consumer Loan Approvals Process. In: La Rosa M., Soffer P. (eds) Business Process Management Workshops, BPM 2012, Lecture Notes in Business Information Processing, Vol 132. pp. 219-220, Springer, Berlin, Heidelberg

[38] Rubin, V. A., Mitsyuk, A. A., Lomazova, I. A., \& Van Der Aalst, W. M. P. (2014). Process mining can be applied to software too!, Proceeding of 8th ACM/IEEE International Symposium on Empirical Software Engineering and Measurement, (ESIM'14, Torino, Italy, September 18-19, 2014), pp. 57/1-8, New York NY: ACM, DOI: http://doi.org/10.1145/2652524.2652583

[39] Van der Aalst, W. M. P., Guo, S., \& Gorissen, P. (2015). Comparative process mining in education: An approach based on process cubes, Lecture Notes in Business Information Processing,Vol. 203, pp. 110-134, Springer, Berlin, Heidelberg, DOI: https://doi.org/10.1007/978-3-662-46436-6_6

[40] Antonelli, D., \& Bruno, G. (2015). Application of process mining and semantic structuring towards a lean healthcare network. IFIP Advances in Information and Communication Technology, Vol. 463, pp. 497-508, Springer, Cham, DOI: http://doi.org/10.1007/978-3-319-24141-8_46

[41] Sztyler, T., Völker, J., Carmona, J., Meier, O., \& Stuckenschmidt, H. (2015). Discovery of personal processes from labeled sensor data - An application of process mining to personalized health care. In CEUR Workshop Proceedings, Vol. 1371, pp. 31-46

[42] Caetano, A., Pinto, P., Mendes, C., da Silva, M. M., \& Borbinha, J. (2015). Analysis of business processes with enterprise ontology and process mining. Lecture Notes in Business Information Processing, Vol. 211, pp. 82-95, Spriger, Cham, DOI: http://doi.org/10.1007/978-3-319-19297-0_6

[43] Heber, E., Hagen, H., \& Schmollinger, M. (2015). Application of process mining for improving adaptivity in case management systems. In Lecture Notes in Informatics (LNI), Proceedings - Series of the Gesellschaft fur Informatik (GI), Vol. 244, pp. 221-231

[44] Mahendrawathi, E. R., Astuti, H. M., \& Nastiti, A., Analysis of Customer Fulfilment with Process Mining: A Case Study in a Telecommunication Company, Procedia Computer Science,Volume 72, 2015, pp. 588-596, ISSN 18770509, DOI: https://doi.org/10.1016/j.procs.2015.12.167

[45] Aisa, V., Kurniati, A. P., \& Yanuar Firdaus, A. W. (2015). Evaluation of the online assessment test using process mining (Case Study: Intensive English Center). In Proceedings of 2015 3rd International Conference on Information and Communication Technology, ICoICT 2015, IEEE, pp. 472-477, DOI: http://doi.org/10.1109/ICoICT.2015.7231470

[46] Riz, G., Santos, E. A. P., \& Loures, E. D. F. R. (2016). process mining to knowledge discovery in healthcare processes, Proceedings of Advances in Transdisciplinary Engineering, Vol. 4, pp. 1019-1028, DOI: http://doi.org/10.3233/978-1-61499-703-0-1019

[47] Vázquez-Barreiros, B., Chapela, D., Mucientes, M., Lama, M., \& Berea, D. (2016). Process mining in IT service management: A case study, In CEUR Workshop Proceedings, Vol. 1592, pp. 16-30

[48] Stefanini, A., Aloini, D., Dulmin, R., \& Mininno, V. (2016). Linking Diagnostic-Related Groups (DRGs) to their processes by process mining. In HEALTHINF 2016 - 9th International Conference on Health Informatics, Proceedings; Part of 9th International Joint Conference on Biomedical Engineering Systems and Technologies, BIOSTEC 2016, pp. 438-443

[49] Epure, E. V., Espen Ingvaldsen, J., Deneckere, R., \& Salinesi, C. (2016). Process mining for recommender strategies support in news media. In Proceedings - International Conference on Research Challenges in Information Science, Vol. 2016-August, DOI: https://doi.org/10.1109/RCIS.2016.7549356

[50] Mahendrawathi, E. R., Zayin, S. O., \& Pamungkas, F. J. (2017). ERP Post Implementation Review with process mining: A Case of Procurement Process. In Procedia Computer Science, Vol. 124, pp. 216-223, DOI: http://doi.org/10.1016/j.procs.2017.12.149

[51] Sladojevic, S., Sladojevic, M., Anderla, A., Mirkovic, M., \& Stefanovic, D. (2018). Data Mining Derived Insights into the Regional Character of Medical Risk Scores. Journal of Medical Imaging and Health Informatics, Vol. 8., No. 2, 2018, pp. 157-166, ISSN: 2156-7018, DOI: https://doi.org/10.1166/jmihi.2018.2320 